suas teorias desenvolvidas em As Américas e a civilizaşão, Darcy Ribeiro compara-nos com outros povos latino-americanos que também estão "em fazimento". A crença no ser humano e no seu povo faz com que termine seu texto, vislumbrando uma "nova Roma" que necessita dominar a "tecnologia da futura civilização, para se fazer uma potência econômica, de progresso auto-sustentado" (p. 449). Se, por um lado, essa crença do autor nos possibilita pensar em uma saída para o Brasil e para o seu povo; por outro, nos traz o seguinte questionamento: como acreditar no futuro, se no passado e mesmo no presente nos converteram em "proletariado externo" (p.441), conforme mostrou o próprio autor?

Darcy Ribeiro, na busca de compreensão do sentido do Brasil, utiliza-se de uma vasta bibliografia nacional e estrangeira. No âmbito nacional, seu texto dialoga com outros, como os de Gilberto Freyre e os de Sérgio Buarque de Hollanda ( para citar apenas alguns) e com seus próprios textos de História e de Antropologia. Dessa forma, O povo brasileiro resgata a memória do autor através de sua ensaística históricoantropológica .

Por essa e por outras formas de diálogo, O povo brasileiro mantém a posição de uma Antropologia crítica que estuda o Brasil para transformá-lo. $\mathrm{Na}$ explicitação de nossa identidade e de nossa alteridade, o livro torna-se mais uma referência obrigatória, impulsionando a leitura crítica do Brasil, do processo de formação do seu povo, dos vários textos ensaísticos de que se valeu Darcy Ribeiro, incluindo aqui sua obra antropológica e até mesmo $O$ povo brasileiro.

Haydée Ribeiro Coelho

UFMG

\section{ALTAS SACANAGENS DE SEBASTIÃO NUNES}

NUNES, Sebastiōo. Sacanagem pura. Sabaró: Dubolso;Mazza, 1995. Somos todos assassinos. 3. ed. Sabará: Dubolso; Mazza, 1995.

O primeiro problema que se apresenta para o leitor de Sacanagem pura e sua contrapartida, Somos todos assassinos (Mazza e Ediçōes Dubolso), é sua indefinição genérica. Onde se deve incluir cada um dos volumes, além da classificação bastante ampla, dada pelo próprio autor, de prosa? Há de se convir que tal indicação não nos leva a lugar algum tendo em vista o conteúdo dos textos de Sacanagem pura e de Somos todos assassinos, já em terceira edição, ou tendo em consideração também sua perigrafia. Além de conter os dois livros, invertidos na forma de impressão, o volume apresenta outras novidades que chocam o leitor menos avisado, a começar pela variação dos nomes do autor: Sebunes Nastião, Sebastunes Nião, Senião Bastunes e, na capa correspondente a Somos todos assassinos, Sebastião Nunes. Esta variação que brinca com o próprio nome do autor antecipa a iconoclastia interna. Na verdade, há dois registros. Um deles, formal, legal, corresponde à parte técnica do livro, com indicação de edição e outros detalhes como revisão, diagramação, composição; dedicatórias; um in memoriam; copyright; endereço; a orelha do livro, com comentários de Fausto Wolff, Gilberto Vasconcelos, Anna Marina, Lívio Xavier, Lázaro Barreto. Tudo isso é uma concessão à praxe, o preço pago por sua inserção num universo cujos valores são bem marcados e, pior que isso, cobrados.

O outro registro começa pelo subtítulo da obra Sacanagem pura, que é "Ensaios sacanas sobre publicidade". Portanto, saímos da indefinição da "prosa" para chegarmos à objetividade do ensaio. Os ensaios se autodefinem: sacanas.

REVISTA DE ESTUDOS DE LITERATURA Belo Horizonte, v. 3, p. $187-204$, out. 95 
Apesar de a sacanagem vir do sistema econômico em que todos estamos e não deles mesmos. Eles são irônicos, gozadores, sarcásticos, mordazes, e todos os adjetivos que caibam numa faixa situada entre o levemente humorístico e o cruelmente satírico. Passando também pelo sado-masoquismo, território em que nos situamos, como ususofredores - categoria de usufruidores compulsórios - da publicidade e, obviamente, da estrutura que a gera. O subtítulo delimita o assunto: publicidade. $\mathrm{Na}$ verdade, os dois livros versam sobre a publicidade. O primeiro, Somos todos assassinos, relata a experiência pessoal do autor como redator de publicidade numa agência, retratando de forma caricata os vários personagens desse universo: o Diretor de Criação, o Diretor Técnico, a Secretária Executiva da Presidência, o Diretor de Arte, o IP (ilustrador português). São retratos do dia-a-dia numa agência de publicidade e uma crítica feroz da falta de escrúpulos em todos os níveis do processo de criação. Ao mesmo tempo, são retratos da falência do povo brasileiro e do processo de manipulação de que é vítima. É também uma demonstração do processo de representação, ideológico, montado pela publicidade. O melhor exemplo será o poema "A felicidade bate à sua porta", que reproduzo integralmente: Todo mundo é feliz/nos anúncios de cigarro./ Todo mundo é feliz/ nos anúncios de bebida./ Todo mundo é feliz/ nos anúncios de carro./Todo mundo é feliz/nos anúncios de tudo./ A melhor garotapropaganda/ da publicidade/ é a felicidade.

Em Sacanagem pura, as epígrafes citadas, de Herbert Marcuse, Albert Camus e de Thorstein Veblen, indicam a linha a ser seguida pelos ensaios: os seres humanos obrigados, como Sísifo, a empurrar eternamente a pedra ladeira acima, incapazes de se livrar dela, condicionados à repetição de estereótipos e à aquisição de bens totalmente desnecessários, que só fazem pesar ainda mais a sua "pedra". Após as epígrafes, vem uma "Nota às traduções das notas", em que o Autor, ironicamente, defende-se de seus possíveis enganos nas traduções, insere-se na moderníssima tradição da intertextualidade (o conceito, pelo menos), e informa aos leitores sua veia para as citações, feitas a mancheias. Em suas palavras: "Desse modo, recortei, modifiquei, mutilei e transformei de tal forma os textos-base que dificilmente poderão ser reconhecidos. Seguindo a lição dos mestres, imagino que possa, de hoje em diante, intitular-me como eles Tradu-Recri-Transcriador". Pode-se ler, nas entrelinhas, críticas aos concretistas paulistas, todos dados a tarefas transcriadoras e que tais. Essa proposta de Sebastião Nunes, ainda que perpassada de ironia, identifica-se com a defendida por Compagnon, teorizador da citação e do recorte, para quem a originalidade deve ser buscada na capacidade que os autores têm de lerem e de modificarem, apropriando-se daquilo que leram.

Ao lado disso, o Autor, numa "Explicação necessária", cita mais uma vez seus gurus, comentando que a bibliografia do volume Sacanagem pura resume-se a oito livros de sete autores, citados à exaustão. E justifica-se: "Estes autores, no entanto, foram escolhidos a dedo por motivos muito pessoais: todos fizeram minha cabeça e todos escreveram em momentos cruciais de nossa historia social. Alguns deles foram também os primeiros a notar a existência de uma perigosa tendência para a padronização e o desperdício." O Autor é de uma sinceridade perigosa, pois ataca, indiretamente, o hábito da Academia de enfeitar suas teses e dissertaçōes com longas bibliografias, o que faz parte de uma encenação do saber. É mais ou menos o provérbio que diz (diria): dize-me com quantos e com quem andas que...

$\mathrm{Na}$ prática, todos se apegam a determinados autores porque, ou eles fizeram a cabeça de quem escreve, ou estão mesmo na moda. O restante é figuração.

Após essa descrição semiótica da perigrafia ou, em outra terminologia, da paratextualidade que cerca o texto 
Disponível em http://www.letras.ufmg.br/poslit

de Sebastião Nunes, vamos ao texto. Esse, nada mais é que uma comprovação de tudo quanto o antecede e prepara: título, capa, nomes do autor, subtítulo, nota, explicação necessária e, até mesmo, um prefácio que usa o título do último livro de Walt Whitman: "Good-bye, my Fancy", travestindo-se de primeiro capítulo. Aqui, mais claramente ainda, como se o tivesse deixado de ser, por acaso, Tião Nunes afunila mais ainda seus propósitos e sua classificação:

Este brevíssimo tratado de sacanagem é um estudo anarchohumorístico sobre a linguagem da publicidade, através da leitura crítica de anúncios impressos e da discussão ao acaso de suas várias estruturas.

Foram usados exemplos rotineiros e mais ou menos recentes década de oitenta - , quando certa aparência de criatividade, louvada até a loucura pela imprensa comprometida com o conceito de que o lucro é o estilo (leia-se toda ela), cedeu lugar a maior rigor funcional, fundado nos estereótipos da comunicação de massa (leia-se: linguagens de controle sobre a maioria), quando o lucro deixou de ser rei para se tornar ditador.

Aliás, é como técnica de comunicação a serviço das ideologias econômicas - e, por extensão, políticas - , que a propaganda deve ser examinada. O que seus ideólogos (e os papagaios dos ideólogos) chamam de criatividade não passa de adequação da mensagem, na época de sua produção, às convenções comportamentais e lingüísticas dominantes da classe média.

A partir daí, começam as análises propriamente ditas, onde Tião Nunes esmiúça as propagandas de empresas como o Bradesco, a Nestlé, Souza Cruz, Hoechst, a Salles Propaganda, a IBM, o Grupo Pão de Açúcar, a Veplan, a General Electric, a Rede Globo, a Calvin Klein, a Good Year, para ficar apenas em algumas. $O$ estilo continua o mesmo: irreverente, contundente, cruel. A linguagem não procura contornos ou desculpas: vai direto ao ponto, à denúncia, à hipocrisia que rege nossas relações sociais e políticas e, por extensāo, as nossas relações pessoais. Mais que uma crítica semiótica das várias propagandas, as palavras de Tião Nunes tecem um retrato de nós, consumidores de terceiro mundo, sujeitos a toda e qualquer manipulação. $\mathrm{E}$, aparentemente, bem informados por uma propaganda também aparentemente de primeiro escalão, publicada em veículos de excelente nível e dirigidas a um público sofisticado, porque com dinheiro
Disponível em http://www.letras.ufmg.br/poslit

suficiente para comprar a revista e porque alfabetizado o bastante para lê-la e, supostamente, comprendê-la e aos anúncios.

As análises não tocam apenas no conteúdo sóciopolítico dos reclames, ou em sua estrutura gráfica e visual. Elas são uma leitura de tudo quanto, em nossa sociedade, é ideologicamente escondido e, ao mesmo tempo, "mostrado". $O$ apelo ao sentimentalismo, ao lugar-comum, a perda de todo e qualquer senso de humanidade e de sensibilidade, a mistificação, "a banalização de situações dramáticas", as pessoas famosas que aparecem vendendo algo nas propagandas tendo como critério apenas o cachê pago, sem se importarem com "o grau de toxidez do veneno, de sacanagem ideológica do anúncio ou de superfluidade da bugiganga", a manipulação de técnicas publicitárias e de "princípios" da publicidade são alguns dos elementos levantados e criticados por Tião Nunes.

As notas bibliográficas que acompanham cada um dos textos de análise funcionam em contraponto, oferecendo uma importante fundamentação teórica sobre os itens sublinhados. Mais que isso, constituem-se em elementos de um diálogo vivo do autor com seus gurus. Para o leitor, são um comentário inteligente, uma leitura mais técnica e uma base científica para a crítica que se lê nos textos.

Sacanagem pura vale pela forma, pelo conteúdo, pelo inusitado muita vez utilizado da linguagem, vale pelo alerta, pela denúncia, pelo humor, pela crueldade com que expõe uma situação de que somos vítimas e de que a publicidade é a vitrine mais ostensiva. Vale, principalmente, pelo modo como desmascara, em cada um de nós, a capacidade de nos deixarmos usar e de reproduzirmos, consciente e inconscientemente, o modelo que aí está.

Luiz Cláudio Vieira de Oliveira

UFMG
REVISTA DE ESTUDOS DE LITERATURA Belo Horizonte, v. 3, p. $187-204$, out. 95
(1) 9 回 